\title{
High Stability of Recombinant Proteins Expressed in Tobacco Chloro- plasts
}

\author{
Andrea Molina and Jon Veramendi*
} Instituto de Agrobiotecnología, Universidad Pública de Navarra-CSIC-Gobierno de Navarra, Campus de Arrosadía,
31006 Pamplona, Spain

\begin{abstract}
The green fluorescent protein and the non-toxic subunit of cholera toxin were expressed in tobacco chloroplasts. Both recombinant proteins accumulated to levels greater than $20 \%$ of the total soluble protein. We did not observe light-dependent induction of gene expression despite employing the promoter and $5^{\prime}$-UTR from the $p s b A$ gene. Both proteins were stable in young and old leaves. The estimated half-life, determined by pulse-chase labeling, was greater than 48 h. Freeze-drying of pulverized leaves supplied an easy method of post-harvest handling with no significant loss of the recombinant protein after 7 months of storage at room temperature. These data suggest that both proteins are good candidates for the expression of fusion proteins (e.g. with antigens) in tobacco chloroplasts.
\end{abstract}

Keywords: Chloroplast transformation, protein stability, CTB, GFP.

\section{INTRODUCTION}

Transgene expression in tobacco plastids reproducibly yields protein levels in a range of 5 to $20 \%$ of the total soluble protein (TSP) [1], although higher levels have been obtained. Protein expression level depends on both production and stability. Subcellular targeting plays an important role in determining the yield of recombinant proteins because the compartment where a protein accumulates can strongly influence the interrelated processes of folding, assembly, and post-translational modification [2]. For example, nuclear encoded proteins have been targeted to the plastid or the secretory pathway using amino-terminal signal sequences and these usually accumulate to higher levels than the same proteins expressed in the cytosol [3-5].

Since a limited set of protein degradation pathways exist in the stroma of plastids [6], it seems conceivable that at least some foreign proteins would not only be produced at higher levels, but would also be more stable inside the chloroplast than in the nucleus or cytoplasmic compartments. However, the extent that protein stability contributes to the high foreign protein accumulation levels in transgenic chloroplasts is currently unknown. In addition, the plastid might be a good location for accumulation of certain proteins or their biosynthetic products that would be harmful to the cell if present in the cytoplasm [4-7].

Gene design for codon optimization in chloroplast transformation yields only a scarce 2- to 3-fold increase in protein accumulation levels, since all codons are used frequently in the plastid [1]. Transcripts synthesized from genes of diverse sources, including bacterial genes with relatively high adenine and thymine [8] or guanine and cytosine content [9], viral genes [10], synthetic mRNAs [8], and plant [11] or

*Address correspondence to this author at the Instituto de Agrobiotecnología, Universidad Pública de Navarra-CSIC-Gobierno de Navarra, Campus de Arrosadía, 31006 Pamplona, Spain; Tel: +34-948-168033; Fax: +34-948232191; E-mail: jon@unavarra.es human cDNAs [12], were stable in plastids. This suggests that the plastid's protein synthesis machinery is compatible with genes from diverse sources, avoiding the need to construct synthetic genes for plastid expression.

We have expressed the non-toxic subunit of cholera toxin (CTB) and the green fluorescent protein (GFP) in tobacco chloroplasts under the control of the promoter and $5^{\prime}$ untranslated region (UTR) of the $p s b A$ gene [13]. These proteins were genetically fused to $2 \mathrm{~L} 21$, a linear antigenic peptide from the VP2 capsid protein of the canine parvovirus (CPV). CTB is widely used as an adjuvant for vaccination and has been expressed in chloroplast at high levels (4\% and $31 \%$ of TSP) with the proper conformation as shown by $\mathrm{G}_{\mathrm{M} 1}$-ganglioside binding activity $[13,14]$. The resulting chimera CTB-2L21 induced antibodies specifically against CPV.

The aim of this work was to analyse the stability of GFP and CTB expressed in the stroma of tobacco chloroplasts. The results indicated that both proteins were highly stable in young and mature leaves with a half-life longer than $48 \mathrm{~h}$. In addition, no loss of recombinant protein was detected after 7 months storage of freeze-dried material.

\section{MATERIALS AND METHODS}

\section{Transplastomic Tobacco Plants}

Transplastomic plants used in this study have been described elsewhere [13]. Briefly, CTB-2L21 and GFP-2L21 under the control of $5^{\prime}$ and $3^{\prime}$-UTRs of the $p s b A$ gene were inserted in the plastid genome by particle bombardment. Integration of the foreign genes into the plastid genome was confirmed by polymerase chain reaction. Homoplasmy was confirmed by Southern blot analysis of $\mathrm{T}_{1}$ generation.

\section{Protein Immunoblot Analysis}

Plants were grown in a phytotron under the following conditions: $28{ }^{\circ} \mathrm{C}, 70 \%$ relative humidity, $16 \mathrm{~h}$ photoperiod, and $250 \mu \mathrm{mol} / \mathrm{m}^{2} / \mathrm{s}$. Leaves from transplastomic plants 
grown in a phytotron were numbered from the bottom of the plant (leaf 1) upwards to the youngest leaves. Leaf samples (100 mg) were harvested $55 \mathrm{~d}$ after transplanting, ground in liquid nitrogen, and resuspended in $500 \mu \mathrm{L}$ of protein extraction buffer (15 mM Na $\mathrm{CO}_{3}, 35 \mathrm{mM} \mathrm{NaHCO} 3, \mathrm{pH}$ 9.6). Soluble leaf extracts $(2 \mu \mathrm{g}$ as determined by the Bradford assay) were boiled for $20 \mathrm{~min}$ in the presence of 2mercaptoethanol and sodium dodecyl sulfate (SDS), and electrophoresed in a $13 \%$ polyacrylamide gel. Separated proteins were transferred to a nitrocellulose membrane for immunoblotting. The primary antibody for detection of the 2L21 epitope (mouse anti-VP2 monoclonal antibody (mAb) 3C9; Ingenasa, Madrid, Spain) was used at $0.5 \mu \mathrm{g} / \mathrm{mL}$, and the secondary antibody (peroxidase conjugated rabbit antimouse IgG, Sigma A9044) was used at a 1:30,000 dilution. The ECL Western blotting system (GE Healthcare) was used for signal detection.

\section{ELISA Quantification of Recombinant Proteins}

Leaf samples (100 mg) from transformed and nontransformed plants grown in a phytotron were ground in liquid nitrogen and resuspended in $500 \mu \mathrm{L}$ of protein extraction buffer. Samples were bound to a 96-well polyvinyl chloride microtiter plate (Costar Corning) overnight at $4{ }^{\circ} \mathrm{C}$. Background was blocked with $1 \%$ BSA in phosphate buffered saline, $\mathrm{pH} 7.4$ and $0.1 \%$ Tween-20 (PBS-T) that also included $1 \%(\mathrm{w} / \mathrm{v})$ skimmed milk (PBS-TM). Wells were incubated with anti-VP2 mAb 3C9 at $0.5 \mu \mathrm{g} / \mathrm{mL}$ in PBS-TM, and then with a 1:50,000 dilution of rabbit anti-mouse IgGperoxidase conjugate in PBS-TM. All incubations were for 1 $\mathrm{h}$ at room temperature. Washes between the different steps were performed with PBS-T. Plates were developed using the peroxidase substrate ABTS (Roche 102 946). The reaction was stopped after $1 \mathrm{~h}$ by the addition of $1 \%$ SDS and the plate read at $405 \mathrm{~nm}$ in a Multiskan microtiter plate reader (Labsystems). A standard curve was created by plating a synthetic 2L21 peptide (Bioworld, Dublin, Ohio, USA) at various amounts ranging form 4 to $31 \mathrm{ng}$ per well in $100 \mathrm{mM}$ $\mathrm{Na}_{2} \mathrm{CO}_{3} \mathrm{pH} 10.5$ to calculate the amount of recombinant protein. Transgenic leaf extracts were diluted to fit in the linear range of the 2L21 standard curve.

\section{Protein Expression After Freeze-Drying}

Transformed leaves from plants grown in a phytotron were harvested and frozen in liquid nitrogen. Freeze-drying (Cryodos-45, Telstar, Spain) was performed for $16 \mathrm{~h}$. Weight reduction during freeze-drying was taken into account and the volume of extraction buffer adjusted accordingly; $30 \mathrm{mg}$ of freeze-dried powder was resuspended in $750 \mu \mathrm{L}$ of protein extraction buffer. ELISA quantification was done to obtain the amount of fusion protein that remained in freeze-dried tissue compared to fresh tissue.

\section{Pulse-Chase Labeling}

Leaf discs $\left(0.97 \mathrm{~cm}^{2}\right)$ from young fully expanded leaves of transformed and non-transformed plants growing in a phytotron were sampled, layered immediately on $0.5 \mathrm{~mL}$ of $\mathrm{Mu}$ rashige and Skoog (1962) (MS) liquid medium, pH 5.8 containing $40 \mu \mathrm{Ci}$ of a ${ }^{35} \mathrm{~S}$-methionine and ${ }^{35} \mathrm{~S}$-cysteine (EXPRESS Protein Labeling Mix, Perkin-Elmer) mixture per leaf disc, and vacuum infiltrated for $3 \mathrm{~min}$. Leaf discs were then illuminated for $30 \mathrm{~min}$ at $25{ }^{\circ} \mathrm{C}$, blotted briefly with blotting paper, rinsed by vacuum infiltration with $2.5 \mathrm{~mL}$ of water per disc, blotted again, and vacuum infiltrated with MS liquid medium containing cold $10 \mathrm{mM}$ methionine and 5 $\mathrm{mM}$ cysteine. Samples were kept in a culture chamber with a $16 \mathrm{~h}$ photoperiod for the different chase periods (up to $96 \mathrm{~h}$ ). Three leaf discs were harvested and frozen in liquid nitrogen per time-point. CTB leaf samples were ground in $150 \mu \mathrm{L}$ of Tris-glycine-SDS buffer with 5\% (v/v) 2-mercaptoethanol and boiled for $10 \mathrm{~min}$. GFP leaf samples were ground in 400 $\mu \mathrm{L}$ of bicarbonate buffer $\left(15 \mathrm{mM} \mathrm{Na}_{2} \mathrm{CO}_{3}, 35 \mathrm{mM} \mathrm{NaHCO}_{3}\right.$, $\mathrm{pH}$ 9.6). Partial purification was performed by ammonium sulphate precipitation. The pellet from the $40-80 \%$ ammonium sulphate precipitation was suspended in a final volume of $100 \mu \mathrm{L}$ of Tris-glycine-SDS buffer with $5 \%(\mathrm{v} / \mathrm{v}) 2$ mercaptoethanol and boiled for $10 \mathrm{~min}$. Protein samples were separated by $13 \%$ SDS-polyacrylamide gel electrophoresis (PAGE). The resulting gels were dried and exposed to film for $4 \mathrm{~d}$.

\section{RESULTS}

Plants transformed with GFP-2L21 showed uniform and intense green fluorescence upon illumination with ultraviolet light (Fig. 1). Mature and young leaves displayed fluorescence of equivalent intensity. The expression of CTB-2L21 $(31.1 \%$ TSP) was higher than that of GFP-2L21 $(22.6 \%$ TSP). The expression of the fusion proteins was dependent on plant age. The maximum levels were obtained at full flowering and the appearance of the first green fruits [13]. The protein expression levels remained constant over five generations in plants grown in the greenhouse (data not shown).

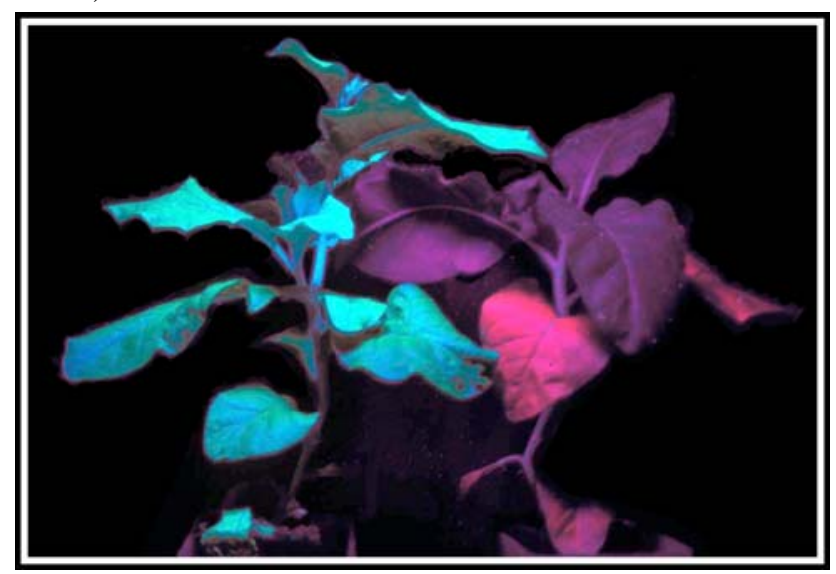

Fig. (1). Fluorescence in transplastomic plants exposed to UV light. The GFP-transformed plant (left) showed green fluorescence and the CTB-transformed plant (right) showed chlorophyll autofluorescence.

Continuous irradiation of plants for $72 \mathrm{~h}$ did not increase protein expression levels (Fig. 2). Even though signals for light-dependent $p s b A$ mRNA translation were localized in the 5'-UTR $[15,16]$ we were not able to detect the expected relationship between expression and light exposure in our plants.

Leaves were numbered from the bottom (leaf 1) upwards to the youngest leaf to determine whether a relationship existed between protein stability and leaf age. TSP content increased from 1 to $5 \mathrm{mg} / \mathrm{ml}$ from leaf 1 to leaf 9 . The same 


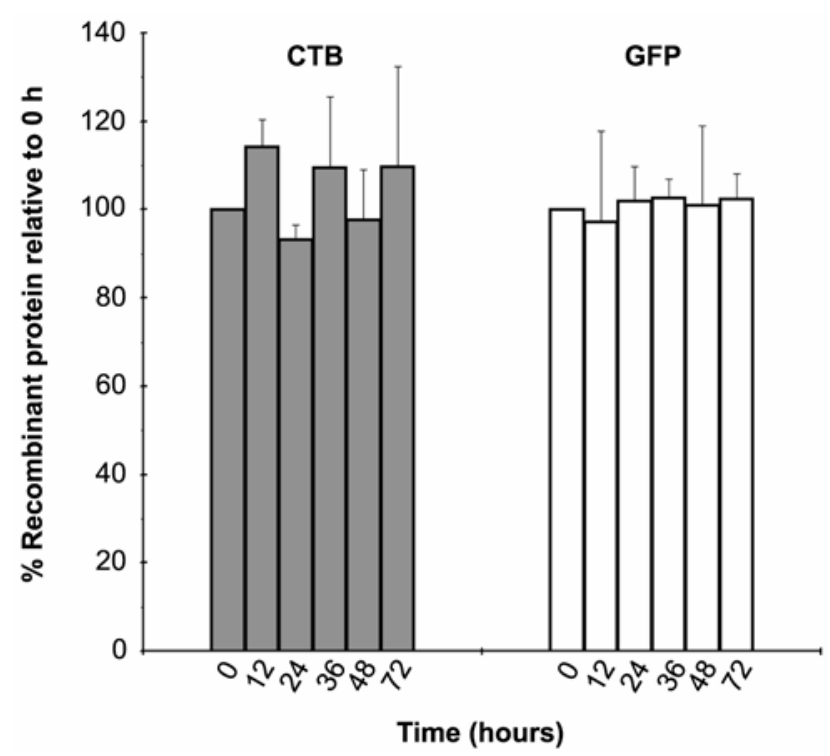

Fig. (2). Expression levels of recombinant proteins exposed to continuous light. Levels were correlated to the expression after $8 \mathrm{~h}$ of dark (point $0 \mathrm{~h}, 100 \%$ ). Plants were subsequently exposed to continuous light for $72 \mathrm{~h}$. Relative percentages were determined at the indicated time. Grey bars correspond to CTB plants and white bars to GFP plants. Data are presented as the means and standard error $(n=3)$.

pattern was observed for the total content of recombinant proteins [13]. The expression levels of recombinant fusion proteins remained approximately constant in all leaves of the whole plant when equal amounts of TSP, $2 \mu \mathrm{g}$, were compared by immunoblot (Fig. 3). This showed that the relative amount of recombinant protein, expressed as a percentage of TSP, did not decline during leaf development, and suggests that CTB and GFP were stable in tobacco chloroplast. In spite of the denaturing conditions of electrophoresis some multimers (dimer and trimer) of CTB were observed (Fig. 3a).

Pulse-chase labeling with ${ }^{35}$ S-methionine and ${ }^{35} \mathrm{~S}$ cysteine was used to investigate the turnover of newly synthesized proteins. Autoradiography of TSP from CTB plant leaf extracts subjected to PAGE showed an intensely labeled band near $14 \mathrm{kDa}$ (Fig. 4a). The Coomassie blue staining confirmed that this band corresponded to CTB because it was absent in the wild-type plant (Fig. 4c). This band did not decrease during the $48 \mathrm{~h}$ chase period, which was consistent with little or no recombinant CTB turnover. In general leaf discs showed tissue damage after $48 \mathrm{~h}$ in liquid culture medium. Tissue degradation was correlated with non-specific protein degradation despite the signal for CTB being present for up to $96 \mathrm{~h}$ (Fig. 4a). TSP extracts from the GFP plant were subjected to ammonium sulphate precipitation (40$80 \%$ ) prior to loading on the gel. The labeled band at $29 \mathrm{kDa}$ corresponded to GFP and was absent in the non-transformed plant (Fig. 4d). This band remained constant during the $48 \mathrm{~h}$ chase period (Fig. 4b). In this case, leaf damage affected GFP protein degradation and no bands were detected after 72 $\mathrm{h}$ of chase. No labeled bands with molecular weights corresponding to CTB or GFP were present in lanes loaded with protein from non-transformed plants regardless whether total a) CTB
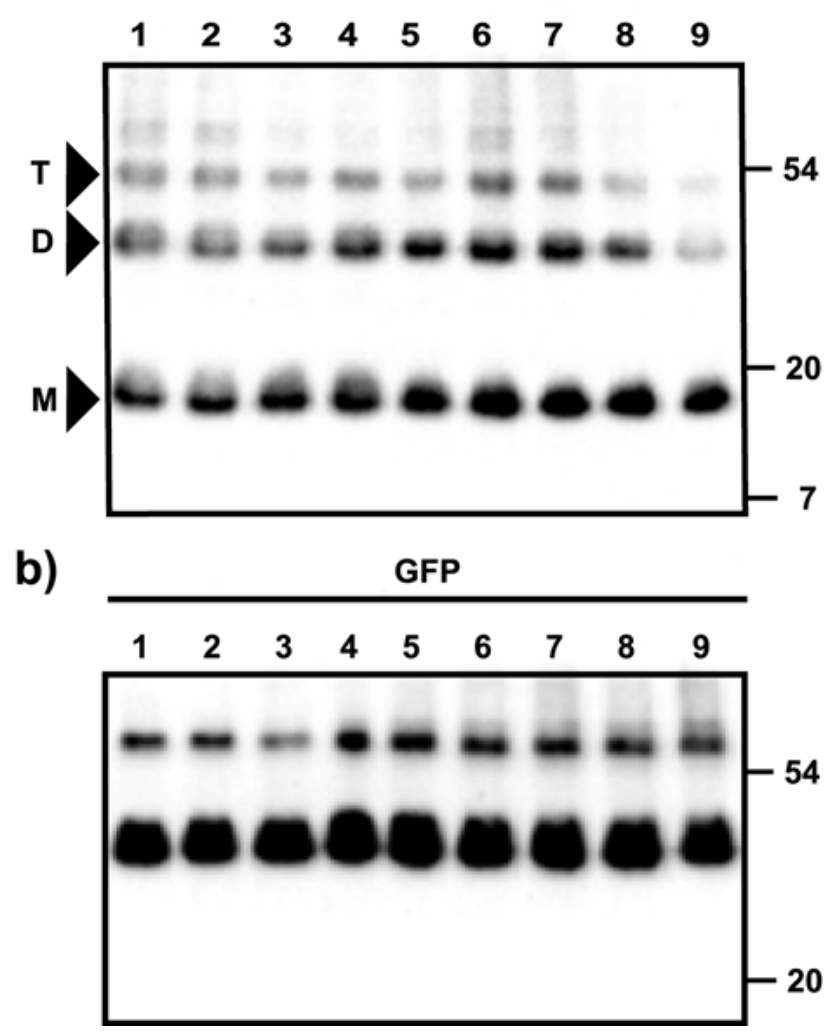

Fig. (3). Immunoblots of total soluble protein extracted from leaves of each type of transplastomic plant. All leaves were sampled $55 \mathrm{~d}$ after transplanting. Leaves were numbered from 1 (oldest) to 9 (youngest). Two $\mu \mathrm{g}$ of total soluble protein were separated by $13 \%$ SDS-PAGE and transferred to a nitrocellulose membrane for immunoblotting with an antibody against the 2L21 epitope, which was fused to the carboxyl-terminus of CTB and GFP. Numbers on the right correspond to the molecular mass $(\mathrm{kDa})$. a) CTB plant proteins showing the monomer (M), the dimer (D) and the trimer (T). b) GFP plant proteins showing the GFP at $29 \mathrm{kDa}$ and its dimer.

or partially purified extracts were used (WT in Fig. 4a, b). Both proteins were stable for at least $48 \mathrm{~h}$, the period during which the discs visually maintained structural integrity in liquid medium.

There was an $80 \%$ reduction in weight of the samples, with respect to the fresh material, during the freeze-drying process. Freeze-dried tissues were stored up to 7 months at room temperature. Analysis of the recombinant protein showed neither a loss during the freeze-drying process nor a loss during storage at room temperature (Fig. 5). In general, GFP showed a slightly more stability than CTB.

\section{DISCUSSION}

One of the main advantages of chloroplast transformation is the potential for accumulation of large quantities of recombinant proteins. These high levels depend on two features of chloroplasts. First, transgenes are hyper-expressed in the chloroplast due to the high copy number of the foreign gene (up to 10,000 copies/cell). Second, the degradation of recombinant proteins in the stroma of the chloroplast must 

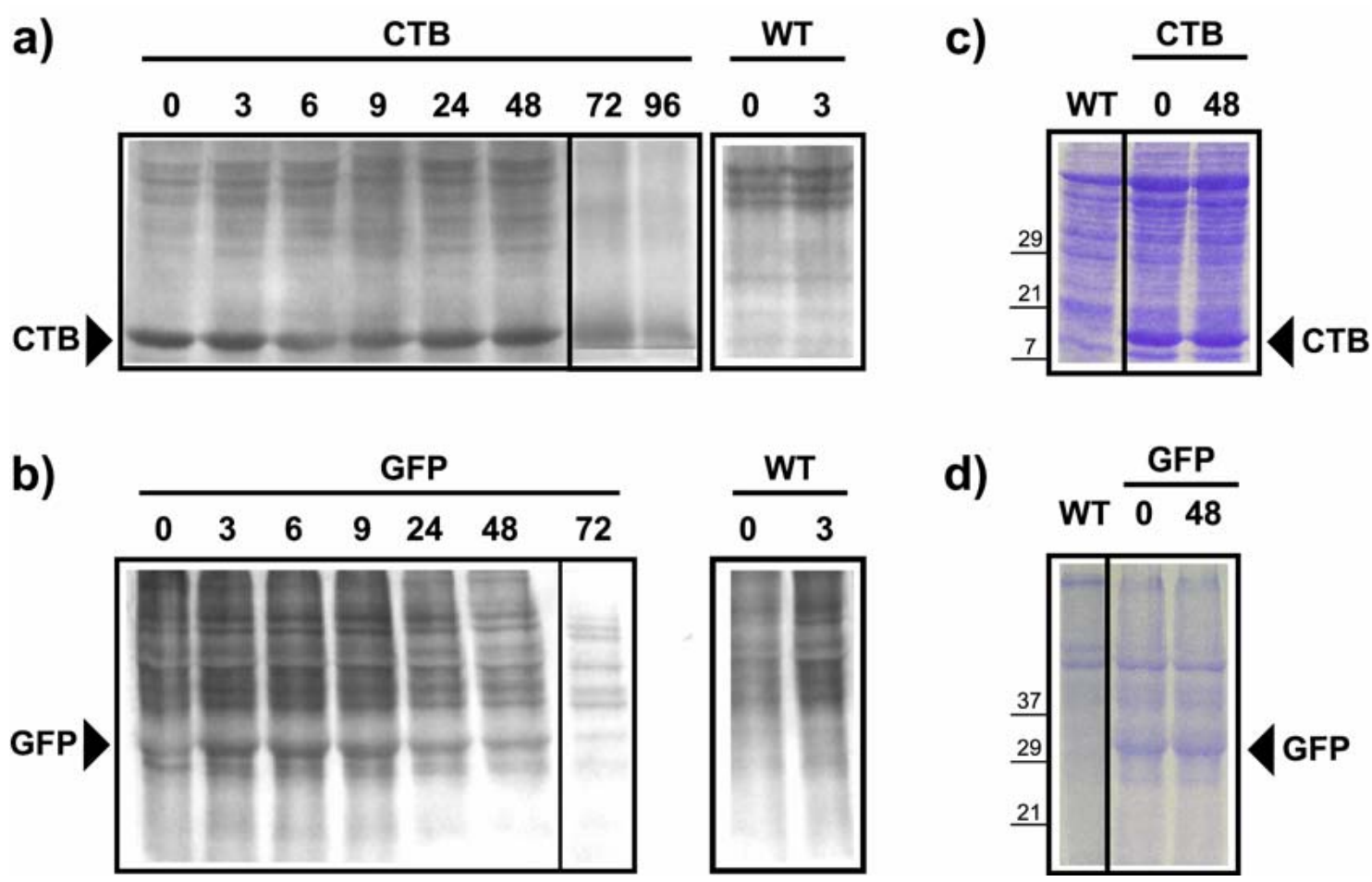

Fig. (4). Stability of GFP and CTB proteins analysed by pulse-chase labeling. Leaf discs were vacuum infiltrated with $35 \mathrm{~S}$, illuminated for $30 \mathrm{~min}$, and washed with cold medium. Samples were collected at the indicated time (h). Autoradiographs of SDS-PAGE gels are shown. a) Total leaf proteins from CTB and non-transformed (WT) discs. b) Partially purified (40-80\% ammonium sulphate precipitation) proteins from GFP and WT discs. Coomassie blue-stained SDS-PAGE gels of CTB (c) or GFP (d) and WT $(0$ h) samples. The same gels were used for autoradiography and staining.

be lower than in the cytosol because of the limited protein degradation pathways present in plastids [6].

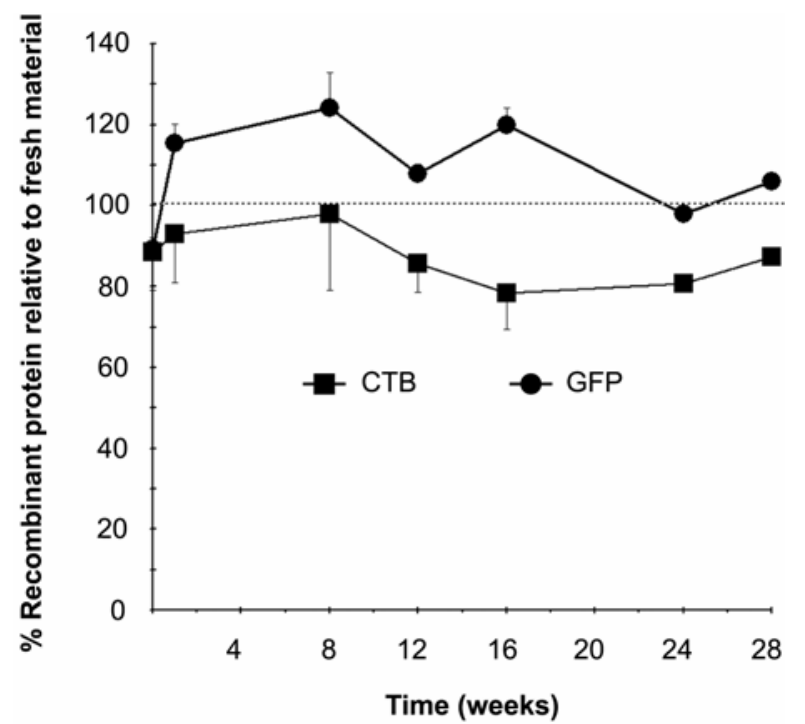

Fig. (5). Effect of freeze-drying and long-term storage on the stability of recombinant proteins. Data were calculated in relation to the protein level before freeze-drying $(100 \%)$. Percentages were determined at the indicated times. Squares correspond to CTB plants and circles to GFP plants. Data are presented as the means and standard error $(n=2)$.

The promoter and 5'-UTR of the plastid $p s b A$ gene were used in producing our constructs. Several authors [15, 16] have shown that the initiation of D1 translation, encoded by this gene, is controlled via psbA 5'-UTR. This regulatory sequence also mediates light-responsiveness, that is translational activation by light and translational arrest in the dark. The in vivo turnover of the D1 protein was estimated at $2 \mathrm{~h}$ [17]. This rapid turnover explains the necessity of enhanced translation (up to 200-fold) of the $p s b A$ gene in the light. An increase in the D1 protein stability might probably mask the light-induced activation of translation. Although we used this regulatory sequence, the influence of light was undetectable (Fig. 2). This might be explained by the much greater stability of GFP or CTB expressed in the stroma of the chloroplast, compared to the D1 protein, which results in a high level of recombinant protein (20-30\% TSP) accumulation and the subsequent negligible influence of light despite lightdependent regulatory sequences.

The analysis of recombinant protein expression by individual leaves of a single plant showed a constant level of expression, relative to TSP, that was independent of leaf age. Pulse-chase experiments showed protein stability lasted longer than $48 \mathrm{~h}$ for newly synthesized GFP or CTB proteins. These data demonstrate the greater stability of both foreign proteins in the stroma of the chloroplast. Other authors have analysed the stability of foreign proteins in this subcellular compartment. Leelavathi et al. [5] expressed the enzyme xylanase in tobacco chloroplasts and showed that leaves dried at $42{ }^{\circ} \mathrm{C}$ retained $85 \%$ of the enzyme activity. In contrast, Birch-Machin et al. [18] reported the first instance of protein instability in the chloroplast. Rotavirus VP6 protein accumulated in cotyledons and young leaves, but declined as the leaf aged. This was most likely due to proteolytic degradation. 
GFP has been previously expressed by chloroplast transformation. Sidorov et al. [19] were the first to demonstrate stable expression of GFP in potato plastids and obtained a maximum expression level of 5\% TSP. Khan and Maliga [20] obtained a high level of GFP expression (18\% TSP) in tobacco chloroplasts, which is equivalent to our results. In both cases, $g f p$ expression was driven by the constitutive promoter $r r n$ (ribosomal RNA operon). Newell et al. [21] analysed the influence of different promoters on GFP expression in tobacco plastids. Plants expressing $g f p$ from the rrn promoter contained approximately 90-fold more GFP (5.5\% TSP) than plants expressing $g f p$ from the $p s b A$ promoter. Despite that the $r r n$ promoter is the most commonly used promoter, our experience has shown the utility of $p s b A$ as a strong promoter, yielding GFP levels over 22\% TSP. We obtained similar expression levels of GFP using the same soluble modified version of GFP (GenBank accession no. U70495) and $3^{\prime}$-UTR of the $p s b A$ gene [20] with only the promoters being different ( $r r n$ or $p s b A$ ). Sheen et al. [22] showed GFP stability for up to $24 \mathrm{~h}$ in the cytosol of maize protoplasts. GFP was stable in our transplastomic plants for at least $48 \mathrm{~h}$, suggesting a higher stability in the stroma of the chloroplast than in the cytosol.

The greater stability of CTB may have been due to its quaternary structure. Pentamerization of CTB is necessary for binding to the intestinal membrane receptor. CTB expressed in tobacco chloroplasts was assembled into oligomers and was biologically active as shown by $\mathrm{G}_{\mathrm{M}_{1}}$ ganglioside binding capacity $[13,14]$. We have shown a high stability of CTB extending to at least $48 \mathrm{~h}$ under our experimental conditions. In addition, the bacterial origin of this protein may also explain the high stability in the chloroplast.

Protein yield is the net result of synthesis and degradation [23], thus protein stability is as important as synthesis. Therefore, increasing the half-life of a recombinant protein in the chloroplast could be one mechanism for increasing the yield of foreign proteins expressed in plants. Oey et al. [24] reported that a phage-derived bactericidal protein was expressed to more than $70 \%$ TSP in tobacco chloroplasts. This was due, to a large extent, to the high stability of this protein inside chloroplasts. Differences in stability may explain the large variations in the accumulation of different foreign proteins in the chloroplast, despite whether the proteins are expressed under the control of the same promoter, terminator, and regulatory sequences. Leelavathi and Reddy [5] showed an increase in the half-life of interferon gamma expressed in tobacco chloroplasts from 6 to $48 \mathrm{~h}$ when its $\mathrm{N}$-terminus was fused to $\beta$-glucuronidase (GUS). Ye et al. [25] showed that a 14-amino acid N-terminal GFP fusion to 5-enolpyruvylshikimate-3-phosphate synthase increased the protein accumulation in transgenic tobacco chloroplasts from 0,3 to $10 \%$ of TSP. Herz et al. [26] observed that a N-terminal fusion-tag of five amino acids yielded the highest expression levels of GUS. The fusion of proteins of low stability to stable proteins seems to be a way around the degradation pathways of the plastid. In addition to the previously mentioned GUS and GFP, we have observed that CTB might also be well suited for generating fusions to stabilize foreign proteins in the stroma of the chloroplast. Moreover, the characteristics of CTB (stable at $60{ }^{\circ} \mathrm{C}$ ) and GFP (stable at $70{ }^{\circ} \mathrm{C}$ and $\mathrm{pH}$ 5.5) (data not shown) facilitate the purification process of recombinant proteins expressed in the chloroplast.
The freeze-drying process provided an easy method for post-harvest handling with no significant loss of recombinant protein (less than 30\%). The pulverized material could be easily and inexpensively stored because it does not require cold-chain storage. This could be very important for oral vaccination, allowing encapsulation or pill formation of freeze-dried material. There are numerous advantages for using plants to produce pharmaceutical proteins. Plants potentially offer extremely cost-effective and efficient production of pharmaceuticals. Protein production in plant cells will probably be safer than traditional techniques because of the lack of contamination with extraneous viral or bacterial materials, mammalian pathogens, or other animal cell-culture contaminants [27]. Due to the enhanced stability in the plastid environment, the expression of foreign proteins in the plastid may be a good alternative to protein expression in seed tissues or storage organs by nuclear transformation.

\section{ACKNOWLEDGEMENTS}

This work was supported by grant BIO2005-00155 from the Ministerio de Educación y Ciencia (Spain). A.M. was a recipient of a fellowship from Departamento de Educación y Cultura (Gobierno de Navarra).

\section{REFERENCES}

[1] Maliga P. Plastid transformation in higher plants. Annu Rev Plant Biol 2004; 55: 289-313.

[2] Fischer R, Stoger E, Schillberg S, Christou P, Twyman RM. Plantbased production of biopharmaceuticals. Curr Opin Plant Biol 2004; 7(2): 152-8.

[3] Di Fiore S, Li Q, Leech MJ, et al. Targeting tryptophan decarboxylase to selected subcellular compartments of tobacco plants affects enzyme stability and in vivo function and leads to a lesion-mimic phenotype. Plant Physiol 2002; 129(3): 1160-9.

[4] Nawrath C, Poirier Y, Somerville C. Targeting of the polyhydroxybutyrate biosynthetic pathway to the plastids of $A$. thaliana results in high levels of polymer acumulation. Proc Natl Acad Sci USA 1994; 91: 12760-4.

[5] Leelavathi S, Reddy V. Chloroplast expression of His-tagged GUSfusions: a general strategy to overproduce and purify foreign proteins using transplastomic plants as bioreactors. Mol Breed 2003; 11(1): 49-58.

[6] Adam Z. Chloroplast proteases: possible regulators of gene expression?. Biochimie 2000; 82(6-7): 647-54

[7] Bogorad L. Engineering chloroplasts: an alternative site for foreign genes, proteins, reactions and products. Trends Biotechnol 2000; 18(6): 257-63.

[8] Tregoning JS, Nixon P, Kuroda H, et al. Expression of tetanus toxin Fragment C in tobacco chloroplasts. Nucleic Acids Res 2003; 31(4): 1174-9.

[9] Lutz KA, Knapp JE, Maliga P. Expression of bar in the plastid genome confers herbicide resistance. Plant Physiol 2001; 125(4): 1585-90.

[10] Fernandez-San Millan A, Ortigosa SM, Hervas-Stubbs S, et al. Human papillomavirus L1 protein expressed in tobacco chloroplasts self-assembles into virus-like particles that are highly immunogenic. Plant Biotech J 2008; 6: 427-41.

[11] Zhang Z, Kallis RP, Ewy RG, Portis AR, Jr. Light modulation of Rubisco in Arabidopsis requires a capacity for redox regulation of the larger Rubisco activase isoform. Proc Natl Acad Sci USA 2002; 99(5): 3330-4.

[12] Fernández-San Millán A, Mingo-Castel AM, Miller M, Daniell H. A chloroplast transgenic approach to hyper-express and purify Human Serum Albumin, a protein susceptible to proteolytic degradation. Plant Biotech J 2003; 1: 71-9.

[13] Molina A, Hervas-Stubbs S, Daniell H, Mingo-Castel AM, Veramendi J. High-yield expression of a viral peptide animal vaccine in transgenic tobacco chloroplasts. Plant Biotech J 2004; 2(2): 141-53.

[14] Daniell H, Lee SB, Panchal T, Wiebe PO. Expression of the native cholera toxin B subunit gene and assembly as functional oligomers 
in transgenic tobacco chloroplasts. J Mol Biol 2001 31; 311(5): 1001-9.

[15] Eibl C, Zou Z, Beck A, Kim M, Mullet J, Koop HU. In vivo analysis of plastid $p s b \mathrm{~A}, r b c \mathrm{~L}$ and $r p l 32$ UTR elements by chloroplast transformation: tobacco plastid gene expression is controlled by modulation of transcript levels and translation efficiency. Plant $\mathbf{J}$ 1999; 19: 333-45.

[16] Staub JM, Maliga P. Translation of psbA mRNA is regulated by light via the 5'-untranslated region in tobacco plastids. Plant J 1994; 6(4): 547-53.

[17] Sundby C, Chow WS, Anderson JM. Effects on photosystem II function, photoinhibition, and plant performance of the spontaneous mutation of serine-264 in the photosystem II reaction center D1 Protein in triazine-resistant Brassica napus L. Plant Physiol 1993; 103(1): 105-13.

[18] Birch-Machin I, Newell CA, Hibberd J, Gray J. Accumulation of rotavirus VP6 protein in chloroplasts of transplastomic tobacco is limited by protein stability. Plant Biotechnol J 2004; 2(3): 261-70.

[19] Sidorov VA, Kasten D, Pang SZ, Hajdukiewicz PTJ, Staub JM, Nehra NS. Stable chloroplast transformation in potato: use of green fluorescent protein as a plastid marker. Plant J 1999; 19(2): 209-16.

[20] Khan MS, Maliga P. Fluorescent antibiotic resistance marker for tracking plastid transformation in higher plants. Nat Biotechnol 1999; 17(9): 910-5.
[21] Newell CA, Birch-Machin I, Hibberd JM, Gray JC. Expression of green fluorescent protein from bacterial and plastid promoters in tobacco chloroplasts. Transgenic Res 2003; 12(5): 631-4.

[22] Sheen J, Hwang S, Niwa Y, Kobayashi H, Galbraith DW. Greenfluorescent protein as a new vital marker in plant cells. Plant J 1995; 8(5): 777-84.

[23] Stevens LH, Stoopen GM, Elbers IJ, et al. Effect of climate conditions and plant developmental stage on the stability of antibodies expressed in transgenic tobacco. Plant Physiol 2000; 124(1): 17382.

[24] Oey M, Lohse M, Kreikemeyer B, Bock R. Exhaustion of the chloroplast protein synthesis capacity by massive expression of a highly stable protein antibiotic. Plant J 2009; 57(3): 436-45.

[25] Ye GN, Hajdukiewicz PT, Broyles D, et al. Plastid-expressed 5enolpyruvylshikimate-3-phosphate synthase genes provide high level glyphosate tolerance in tobacco. Plant J 2001; 25(3): 261-70.

[26] Herz S, Fussl M, Steiger S, Koop HU. Development of novel types of plastid transformation vectors and evaluation of factors controlling expression. Transgenic Res 2005; 14(6): 969-82.

[27] Peterson RK, Arntzen CJ. On risk and plant-based biopharmaceuticals. Trends Biotechnol 2004; 22(2): 64-6.

(C) Molina and Veramendi; Licensee Bentham Open.

This is an open access article licensed under the terms of the Creative Commons Attribution Non-Commercial License (http://creativecommons.org/licenses/by-nc/3.0/) which permits unrestricted, non-commercial use, distribution and reproduction in any medium, provided the work is properly cited. 